and mangrove swamps seem to be little different from others in the same region. No fresh light is thrown on their origin. They differ mainly from Indo-Pacific reefs in the shallowness of the lagoons-seldom more than ten fathoms-within the barrier reefs, but, unfortunately, in an otherwise well-got-up book, the chart given is totally inadequate.

Some of the party were more interested in the land than in the sea, and much of their time was spent in hunting for land-shells. It is upon the great limestone ridges (sierras) which stretch through Cuba from east to west that that island's astounding wealth of land mollusca is found. In addition, there are isolated mounds of limestone (mogotes), rich in peculiar genera and species. The author is an authority on these, and we are sorry not to hear much more of them. Clearly he considers that the land mollusca reached their climax after the elevation of the limestones, apart from which they cannot maintain themselves. Later, abrasion has been at work, and their original range has dwindled as continuous limestone areas were replaced by broken sierras and isolated mogotes. Isolation in plastic genera gave rise to the formation of new species. The widely distributed families, genera, and species are hence the ancient forms, the isolated genera and species their modern descendants.

The Statesman's Year-Book. Statistical and Historical Annual of the States of the World for the year I9I6. Edited by Dr. J. Scott Keltie, assisted by Dr. M. Epstein. Pp. xliv + I56o+ maps 4. (London: Macmillan and Co., Ltd.) Price ros. $6 d$. net.

THE "Statesman's Year-Book" makes its everwelcome appearance. The editors, Dr. Scott Keltie and Dr. Epstein, have been able to obtain much statistical information regarding the belligerent countries, and, in the case of Germany, to include facts and figures based upon the latest officially published information. Maps show the railway schemes in Asiatic Turkey and in Africa respectively, and the distribution of Germans both in the world as a whole and, in greater detail, in the United States. The introductory tables provide a world review of the production of wheat, sugar, ships, etc., and usually include the year under review. There is an illuminating summary which deals with the Great War in regard to population, books, loans, and war finance. The Allies outnumber the Central Empire Alliance by 5 to $I$; the war has cost already more than ro,000,000.00ol., of which a quarter has been spent by Britain, nearly a quarter by Germany, and a fifth by Russia. Mr. John Leyland has revised the information concerning the navies of the world in succession to the late Mr. Fred $\mathrm{T}$. Jane. We cull a few facts at random: There is a volunteer corps among the $23^{2} 8$ males in the Falkland Islands; Oregon University, organised in 1876 , has 108 professors; the Free City of Bremen in roi3 exported goods valued at Io, I ro,oool. to Great Britain, about 9 per cent. of the total exports of the port.
LETTERS TO THE EDITOR.

[The Editor does not hold himself responsible fur opinions expressed by his correspondents. Neither can he undertake to return, or to correspond with the writers of, rejected manuscripts intended for this or any other part of NaTuRE. No notice is taken of anonymous communications.]

\section{Is Proto-Oxygen the Principal Constituent of the Atoms?}

As from Moseley's experiments we know the number of rare-earth elements between $\mathrm{La}$ and $\mathrm{Ta}$ to be I5, the mean difference between atomic weights is, from $\mathrm{Mg}$ on, for 6 atomic numbers, I6 exactly. So for Mg (Atw. 24, N I2) and Th (Atw. 232, N 90) we get $(232-24) / 16=(90-12) / 6=13$. Between $U$ and $\mathrm{Nt}$ this difference of $238-222=16$ is known to be a difference of $4 \alpha+2 \beta$ particles. But if the $\alpha$ particle is the real constituent of the atoms, $4 \alpha+2 \beta$ is the inner part of the oxygen atom (the additional $6 \beta$ particles being electrons of valency). That atomic weights are not twice the atomic numbers would be due thus to the formation of $\alpha_{4} \beta_{2}=\theta$ particles, or proto-oxygen, within the nucleus, and radio-activity should be the disintegration of these $\theta$ particles into their constituents. It may be remarked that $\alpha_{4} \beta_{2}=\theta$ is similar to $\mathrm{H}_{4}^{+} \beta_{2}=\alpha$ (which might be the formula for the $\alpha$ particle).

Gorsel, Holland, July 17 .

International Commission on Zoological Nomenclature.

OpINIONs on the following subjects are before the International Commission on Zoological Nomenclature for final vote:-

Opinion 7o.--The case of Libellula americana, L., 1758 , vs. Libellula americanum, Drury, I773.

Opinion 7r.--Interpretation of the expression "typical species" in Westwood's ( 1840 ) synopsis.

Opinion 72.-Herrera's zoological formulæ.

Opinion 73.-Five generic names in Crinoidea, ninety-two generic names in Crustacea, and eight generic names in Acarina, placed in the official list of generic names.

If anyone is interested in these opinions and has not already been reached by the Commission, and therefore has not had an opportunity of being heard upon them, he is cordially invited to send his views to the Secretary of the Commission, and if any new point is raised that is likely to alter the opinion of the Commission, the data will be forwarded to the Cormmissioners for consideration.

$$
\text { C. W. Stiles, }
$$

Secretary to the Commission.

Office of Secretary to International Commission on Zoological Nomenclature,

Smithsonian Institution, Washington, D.C., July I3.

\section{The Magnitude of $\theta$ Eridani.}

The arguments of Mr. E. J. Webb (Nature, vol. xcvii., p. 34I) seem conclusive as to this star having been of the first magnitude at the epoch of Ptolemy's catalogue, but are perhaps less conclusive as to its magnitude at any other time, though the reviewer of Peters's and Knobel's work is surely wrong in assuming that Al Sûfi would find any difficulty in judging between a first and a third magnitude star at an altitude of $10^{\circ}$. Have astronomers considered the possibility of $\theta$ Eridani having been practically a temporary star at Ptolemy's epoch? Do Peters and Knobel come to any conclusion as to the magnitude of this star? T. W. BACkHOUse.

West Hendon House, Sunderland, August 4.

$$
\text { No. 244I, VOL. 97] }
$$

